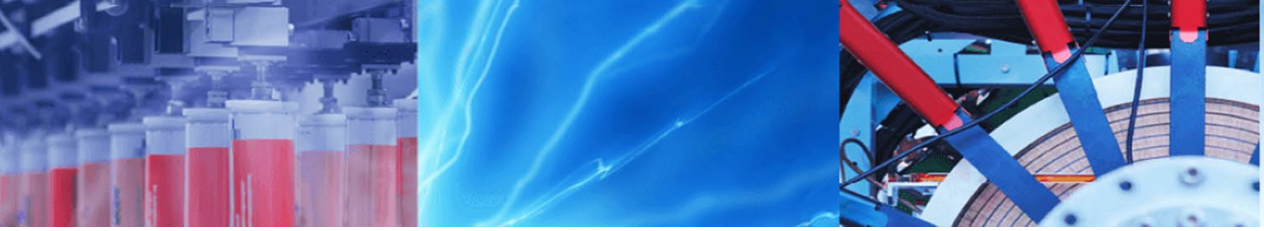

Research Article

\title{
Product models in embodiment design: an investigation of challenges and opportunities
}

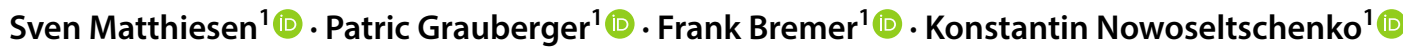

(c) Springer Nature Switzerland AG 2019

\begin{abstract}
In product development, many different models of the product and the development process exist. In the phase of embodiment design, models of the product are essential. Finding a suitable product model for an embodiment design task can be challenging, because many different models are available. The aim of this contribution is to categorize existing product models in embodiment design and to develop an initial approach to structured product model selection. The product models are obtained from a systematic literature review. Criteria for structuring are derived from similar research into process models and interdisciplinary models for product development. The identified models are categorized in an overview and a tabular detailed analysis of their characteristics. A guideline on how to identify suitable models using the overview and table is developed. This guideline is explained with a structured product model selection process being used as an example. To sum up, this contribution is to initially support design engineers in choosing suitable models for their tasks.
\end{abstract}

Keywords Product development · Embodiment design · Product model · Design research

\section{Introduction}

Use of models in product development is mandatory, since the original product does not exist until the development is completed. Product developers have to use many different models to fulfill their tasks. In this contribution, the basic understanding of a model follows the definitions of Stachowiak [1] and Andreasen et al. [2]. According to Stachowiak, all models have the basic characteristics of reduction, pragmatism, and representation of an original [1]. Andreasen et al. describe models as a depiction of an object or phenomenon with similar properties [2]. Models used in product development can be divided into models of the product and models of processes. Models of processes often are of methodological character and are investigated and improved through research. Examples of such models are the VDI2221 [3], the "Münchner Vorgehensmodell" MVM [4], the "Autogenetic Design Theory" [5], or the "integrated Product engineering Model" (iPeM) [6]. A structured overview of these models is given by Wynn and Clarkson [7], who categorize models of the design and development process based on scope and type.

Models of the product, on the other hand, are mostly tool-based and the methods for using them, if they exist at all, focus on how to use the tool (for example, CAD, multi-body simulation, etc.). Ehrlenspiel and Meerkamm outline that many different models with different levels of abstraction, perspectives, and representation modes exist to describe products in product development $[8, \mathrm{pp}$. 34-37]. Model building enables the pragmatic reduction of a real problem to the essential and therefore is necessary for successful embodiment design [1]. During model building, certain characteristics of the product have to be excluded in order to control model complexity.

Design engineers have to be aware of the uncertainty in model building and usage, as models cannot contain

Patric Grauberger, Patric.grauberger@kit.edu | ${ }^{1}$ IPEK - Institute of Product Engineering, Karlsruhe Institute of Technology (KIT), Kaiserstr. 10, 76131 Karlsruhe, Germany.

SN Applied Sciences (2019) 1:1078 | https://doi.org/10.1007/s42452-019-1115-y 
all characteristics of the original. In choosing a model for a task, they also choose the uncertainties associated with the model's characteristics and range. The focus of this research is on the variety of product models used in embodiment design and the different aspects of the product considered in these models.

In the embodiment design phase, design engineers define a product's embodiment that is supposed to fulfill the functional requirements specified for the product under boundary conditions, such as the production costs and legal requirements. Design engineers create mental product models of how a product's embodiment has to be defined to fulfill its functions. Experienced design engineers are often able to build powerful mental models of the product $[9, p .8]$ that support them in fulfilling the tasks necessary to define the embodiment. From these mental models, explicit models like sketches, prototypes, finite element method simulation models, and many others are derived. These models are used as tools and documentation of the design results $[2$, p. 40]. However, much of the knowledge contained in the mental models remains implicit, as it is not needed to complete the explicit model. For example, many of the thoughts of a design engineer while defining a CAD model are not documented, as it is only necessary to define parameters and not to give a reason why they are defined this way. When a model is built, some of the insights gained may not be integrated into the explicit model, as their documentation is not supported. When the influence of a tolerance width is investigated, for example, the identified tolerance that has to be maintained in manufacturing can be documented in the product model "technical drawing". The reason why this tolerance was chosen remains implicit, as it is not important for manufacturing and the product model contains no element to store this information.

The need to support thought processes of design engineers was described by Matthiesen [10, p. 5]. One way to support these processes is to provide suitable models that enable design engineers to explain their knowledge and insights. These models have to contain suitable elements to express the mental model. When no suitable model is available or known, new models are developed by research organizations and companies. However, these models often are insular solutions, as it remains unclear whether suitable models already exist and where connectivity might be possible.

To support design engineers in identifying suitable models from the pool of already existing models, differentiation is necessary. Andreasen et al. outline that it is possible to differentiate models in product development according to their purpose [2]. In his doctoral thesis, Fuchs differentiates models in product development according to their content, structure, and purpose to support model selection in problem solution processes [11]. For process models, a framework exists for researchers to position their models and practitioners to gain an overview of these models [7]. For industry-relevant product models in the field of mechatronic design, overlapping usage was studied in the disciplines of mechanical, electrical, and software engineering of mechatronic product development [12]. This work reveals that research into model structuring approaches is important in product development.

In embodiment design, however, a structure that enables an overview and clusters product models according to the needs of design engineers is still lacking. It is a great challenge to find a suitable model from the plethora of existing product models in embodiment design. The research presented here is aimed at developing a framework and categorization scheme similar to that in the field of process models. A first step towards developing such a method is gathering a set of models relevant to embodiment design. Knowing that no complete set of these models can be obtained, the first research question arises:

Research question 1: Which product models are currently used or developed in embodiment design research?

To answer this question, a structured literature review is carried out. The product models found by the literature review are structured by using categories derived from prior research in the field of modeling in engineering design. This collection then has to be made usable in embodiment design, as the categorized collection alone hardly allows an overview to be obtained by design engineers. This gives rise to the second research question:

Research question 2: Are the proposed categories suited for an application-oriented categorization of product models for embodiment design?

To investigate this research question, a framework and a tabular overview of product models are generated as categorization. Following this investigation, a guideline is developed to explore challenges as well as opportunities associated with the model selection process. It outlines how the product model selection process of design engineers could be supported. The result of this contribution is a categorization of product models in embodiment design and a suggestion for a structured product model selection process.

\section{Materials and methods}

To investigate research question 1 , a systematic literature research approach is used. The results are processed and categorized to differentiate product models in design 
engineering based on studies by Weidmann et al. [12] and Wynn and Clarkson [7]. In the following subsections, the methods and materials used are described in further detail.

\subsection{Systematic literature research}

Systematic literature research is based on the method developed by Dresch et al. [13] and depicted in Fig. 1.

The literature review flowchart defines the activities during research. The first step of the systematic literature review is question definition and mindset. The research question defines the scope and depth of the investigation. The derivation of research questions for this contribution is described in the introduction above. The subject area in which the research questions are dealt with is restricted to the relevant topics according to the defined mindset. In this case, the subject area is defined as embodiment design, which also is described in the introduction.

The research strategy includes the search terms and the sources considered. For research, the following terms have been used based on the understanding of embodiment design and activities in embodiment design described by Pahl et al. [14] and Matthiesen [15]: embodiment design, product model, embodiment function relation, function model*, system* modeling, embodiment design AND model, embodiment design AND analysis, embodiment design AND synthesis. The search terms are used in open access databases as well as in databases with restricted access. The databases used are Researchgate, Scopus, TEMA, IEEE, ASME digital collection, Web of Science, and google scholar. The citavi 6 software (www. citavi.com) serves as a platform for documenting the identified articles and references.

The publications found in Research are further processed based on their Eligibility. Duplicate articles are identified automatically through their citation data. The initial criteria for the inclusion in the citavi project are:
1. Published after 2008 , as models mentioned in the last 10 years are considered as currently used or subject to research in accordance with the research question.

2. Published in the field of design engineering, as only product models relevant to embodiment design are the subject of research.

3. Published in English, as models that are accessible on international platforms are considered relevant to the design engineering community.

To fit the initial criteria, filters of the databases used are applied. Over all databases and search terms, 1093 source titles are obtained. To evaluate the eligibility of the publications, the following inclusion criteria are formulated for the initial screening of title and abstract. The publications are included, if they fulfill all of the following criteria:

1. Mentioning of a product model or modeling process in the abstract and/or title

2. Context of embodiment design is indicated by keywords

After this screening process, 140 papers remain for full text analysis. For this analysis, additional inclusion criteria are added:

1. The described model is a product model.

2. The type of depiction and the type of information provided by the model are described in the paper.

3. The minimum quality for the publications to be included is publishing in a peer-reviewed journal or conference proceedings.

Full text analysis produces 48 publications for the result table (see Table 2). The result table for the product models is obtained by further processing of the publications according to the criteria identified for structuring product models in Sect. 3.1. The results are synthesized in the form of the differentiation of the product models presented in Sect. 3.2.

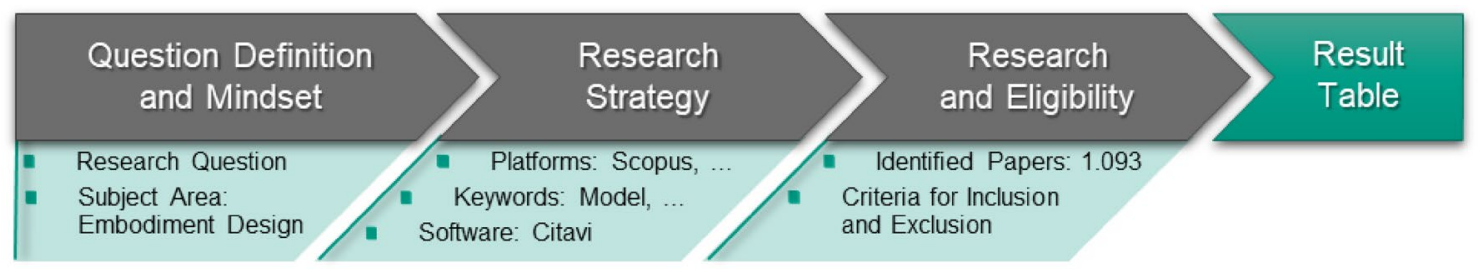

Fig. 1 Structure of the research methodology based on Dresch et al. [13] 


\subsection{Product model differentiation}

The method to differentiate the product models is based on similar model categorization work. Weidmann et al. [12] categorize product models for mechatronic design according to discipline, type of depiction, engineering phase, and type of information. These categories are used to structure the research results in detail and give an overview of their focus and range. From this approach, the categories are derived to differentiate the product models used in embodiment design. Table 1 shows the template of the table of product models with these categories. A description of the categories is given in the following subsection.

\subsubsection{Type of depiction}

Following the definition of Weidmann et al. in mechatronic design [12], product models are differentiated according to their type of depiction. Weidmann et al. distinguish between analytical, graphical, table/matrix, textual, and physical representations of the product. Analytical representations are solvable mathematical representations or program codes. Graphical representations contain visual depictions close to the real product as well as symbolic and simplified depictions. Table/matrix summarizes the representations using categories to structure the model. The structure has to be defined as well as the way to obtain the input, e.g. an analysis method. Depiction in textual form means any kind of prose and a physical depiction means a physical model, e.g. a prototype.

\subsubsection{Type of information}

The four categories of information are function, behavior, qualitative embodiment, and quantitative embodiment. They are based on Weidmann et al. [12] and adapted to embodiment design using more detailed categories from Pahl/Beitz [14] and Matthiesen [15]. The basic terms function and behavior are used according to [16].

The category of function describes the teleological aspect of a system. It specifies the purpose of a system and is not necessarily dependent on its embodiment. This understanding of function is also known as intended behavior. The category of behavior contains a description of what can be observed in the system. The behavior

Table 1 Template of the table of product models

\begin{tabular}{|c|c|c|c|c|c|c|c|c|c|c|}
\hline \multirow[b]{2}{*}{$\#$} & \multirow[b]{2}{*}{$\begin{array}{l}\text { Product Model } \\
\text { (Source) }\end{array}$} & \multicolumn{5}{|c|}{ Type of depiction } & \multicolumn{4}{|c|}{$\begin{array}{c}\text { Type of } \\
\text { information }\end{array}$} \\
\hline & & 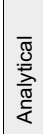 & 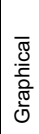 & 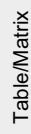 & 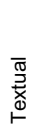 & $\begin{array}{l}\bar{\pi} \\
\frac{\pi}{0} \\
\frac{2}{0}\end{array}$ & 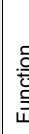 & 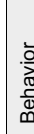 & 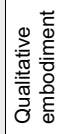 & 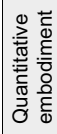 \\
\hline & Example model & & & & & & & & & \\
\hline
\end{tabular}

is directly dependent on its embodiment and typically includes a measure of how well the function (intended behavior) is fulfilled. In embodiment design, it is important to distinguish between qualitative and quantitative embodiment. The categories of embodiment extend the definition of structure by Gero and Kannengiesser, who describe it as "what the artefact consists of" [16]. The differentiation of quantitative or qualitative embodiment is necessary to differentiate models for concept and design phases. The information has to include values of parameters to be considered as a quantitative embodiment representation. The specification of components or description of parameters without assigned values as a necessary part of the model is referred to as qualitative representation.

\subsection{Building the product model framework}

As a basic structure, the framework for design and development process (DDP) models by Wynn and Clarkson [7] is used. This framework gives an overview of the levels and varieties of process models for product development. It contains the dimensions of model scope and model type that are differentiated into more detailed categories [7, p. 164]. Models for products and product development processes exhibit certain similarities, as they can be categorized in a common framework (compare doctoral thesis by Fuchs [11]). He distinguishes product and process models according to the categories of contentwise orientation, structural orientation, and purpose. The scope dimension of the framework for product models is based on the "engineering phase" of Weidmann et al. [12]. It is further differentiated and limited to the two phases "concept" and "design" of embodiment design. In the concept phase, ideas about the product as well as requirements from the market exist, while a parameterized product is not available. In the design phase, parameters of the product are already defined, e.g. in CAD models or technical drawings. To fill the "model type" dimension with appropriate criteria for product models, the dimension of "model application" from Andreasen et al. [2] is used, which differentiates product models according to their application and enables the evaluation of their purpose.

The engineering phases according to Weidmann et al. [12] are summarized by design \& concept and design, as all product models identified for the concept phase can also be used in later design phases. On the other hand, product models that need a complete and/or quantitative representation of the product can only address the design phase, because the concept has to be defined already. Product models for the concept phase also work for tasks in the design phase, but can also depict an idea without a reference product or the object of the design task itself being needed for the model building process. 
The five modeling application categories selected as dimension for the product model framework are capture the unknown, define the design, communication, obtain insight, and manage. They describe different application purposes while the design process progresses [2]. Capture the unknown means that a product model is used to explain an idea or a mental model of the product. The externalization during the synthesis process is the key to this feature of a product model. These product models can be used to evaluate the principle of the design. Define the design means that the product model supports the process of product specification. This enables the designer to transfer the characteristics to the manufacturing documentation or other product models. Product models that are an aid in communication do not have a closely defined specification. The core requirement is that the product model supports communication. The product model has to be adequate to describe the properties and the purpose of the object to the receiver of the communication. Communication is not included in the framework, as all the identified models contain aspects of communication, which is why it is not considered suited for differentiating models. Product models that help to obtain insight enable the designer to further clarify the solution or to create knowledge about the relations between characteristics and properties without the production of a full-scale prototype. The last subcategory manage includes product models that support the design processes. These models are used to give the design a structure, including interaction, interfaces, and dependencies of individual parts of the products. To sum up, models supporting management give an overview of the product as a system and enable the engineering team to define work packages or user stories. [2], pp. 44-51.

The systematic approach to filling the framework is based on the following questions. First, the engineering phase is assigned using two questions based on Weidmann et al. [12] and Matthiesen [15]. Then, the modeling application is tested using eight questions (two per area, based on Andreasen et al. [2]):

Design or design \& concept

a. Does the product model need quantitative information about the dimensions and material of the embodiment? (Yes = design; $\mathrm{No}=$ design \& concept)

b. Do you need a defined product to build the initial product model through analysis? (Yes=design; No $=$ design $\&$ concept)

Modeling application

a. Can the product model be used in the synthesis of design? (Yes = capture the unknown) b. Can the product model be used for ideation? (Yes = capture the unknown)

c. Can the product be structured in subsystems with the model? (Yes = manage)

d. Can the product model support the management of design activity? (Yes = manage)

e. Can the product model be used to depict requirements? (Yes = define the design)

$\mathrm{f}$. Is the product specified in the product model? (Yes= define the design)

g. Can the product model be used to gain more knowledge about the relations of embodiment and function or behavior? (Yes= obtain insight)

h. Can the product model be used to validate the product? (Yes = obtain insight)

In case of product models being applicable to more than one clusters, discussion with experts on product models is planned.

\subsection{Derivation of the guideline}

Since neither the differentiation in Table 1 nor the framework (see Sect. 2.3) provide a structured approach or provide enough information on how to select a product model, a guideline is derived. This guideline is to methodically support the decision process during product model selection. It utilizes the framework (Sect. 2.3) and product model differentiation (Table 1) to provide the information needed. The presented guideline is an approach to selecting product models in a structured manner. In this stage, however, it may only be a starting point for future research on the product model selection process.

\section{Results of the literature review}

In this section, the results of the literature review are presented. A framework is derived based on the described dimensions of modeling purpose and engineering phase and the identified product models are integrated. For this, questions taken from Andreasen et al. [2] are used. In addition, the product models are assigned to categories from the table of product models (Table 2). A guideline that connects the framework with the table of product models is presented.

\subsection{Product models in embodiment design}

For a better understanding, the Framework cluster column is added to the template of the table of product models shown in Table 1. The product models obtained from the systematic literature review are then listed (see Table 2). 
Table 2 Categorized product models table

\begin{tabular}{|c|c|c|c|c|c|c|c|c|c|c|c|}
\hline & & & ype & f de & pictic & & Typ & e of & inform & nation & \\
\hline$\#$ & $\begin{array}{l}\text { Product Model } \\
\text { (Abbreviation) } \\
\text { (Source) }\end{array}$ & 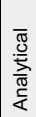 & 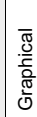 & 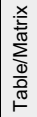 & 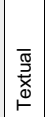 & 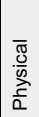 & 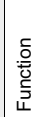 & 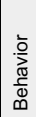 & 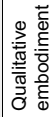 & 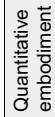 & 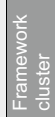 \\
\hline 1 & $\begin{array}{l}\text { 2D / 3D CAD }{ }^{1} \text { Models } \\
{[17][18][19]}\end{array}$ & & $x$ & & & & & & & $x$ & II \\
\hline 2 & $\begin{array}{l}\text { Axiomatic Design Model } \\
{[20]}\end{array}$ & $x$ & & $x$ & & & $x$ & & & $x$ & II \\
\hline 3 & $\begin{array}{l}\text { Behavioral Matrix } \\
\text { [21] }\end{array}$ & $x$ & & $x$ & & & & $x$ & & $x$ & VI \\
\hline 4 & $\begin{array}{l}\text { Bond Graph Model } \\
\text { [22] }\end{array}$ & & $x$ & $x$ & & & & $x$ & $x$ & & II \\
\hline 5 & $\begin{array}{l}\text { C\&C }^{2} \text { Model }^{2} \text { (C\&C } \\
{[23][24][25]}\end{array}$ & & $x$ & & & & $x$ & $x$ & $x$ & & III \\
\hline 6 & $\begin{array}{l}\text { Connectivity Graph } \\
{[26]}\end{array}$ & & $x$ & $x$ & & & & & $x$ & & II \\
\hline 7 & $\begin{array}{l}\mathbf{C P M}^{3} \\
{[27][28][29] \quad[30]}\end{array}$ & & $x$ & $x$ & & & & $x$ & $x$ & & II \\
\hline 8 & $\begin{array}{l}\text { Design Structure Matrix (DSM) } \\
{[31][32][33]}\end{array}$ & & & $x$ & & & $x$ & $x$ & $x$ & & $\mathrm{VI}$ \\
\hline 9 & $\begin{array}{l}\text { Digital Mock-Up } \\
{[34][35]}\end{array}$ & $x$ & $x$ & & & & & $x$ & & $x$ & III \\
\hline 10 & $\begin{array}{l}\text { FEM }{ }^{4} \text { Simulation Model (FEM) } \\
{[34][36][18]}\end{array}$ & $x$ & $x$ & & & & & $x$ & & $x$ & VII \\
\hline 11 & $\begin{array}{l}\text { Function Structure } \\
{[26][37]}\end{array}$ & & $x$ & & & & $x$ & & & & $\mathrm{VI}$ \\
\hline 12 & $\begin{array}{l}\text { Function Trees } \\
{[38]}\end{array}$ & & $x$ & & & & $x$ & & & & VI \\
\hline 13 & $\begin{array}{l}\text { Integrated Function Model (IF } \\
\text { Model) } \\
{[39]}\end{array}$ & & $x$ & $x$ & & & $x$ & $x$ & $x$ & $x$ & VIII \\
\hline 14 & $\begin{array}{l}\text { Kinematic Model } \\
{[40]}\end{array}$ & $x$ & $x$ & & & & & $x$ & & $x$ & I \\
\hline 15 & $\begin{array}{l}\text { Model of Langeveld (Langeveld) } \\
\text { [41] }\end{array}$ & & $x$ & & & & $x$ & & $x$ & & IV \\
\hline 16 & $\begin{array}{l}\text { Models according to } \mathrm{He}(\mathrm{He}) \\
{[42][43][44]}\end{array}$ & & $x$ & & & & $x$ & & $x$ & & II \\
\hline 17 & $\begin{array}{l}\text { Models based on Gero (Gero) } \\
{[45][46][47]}\end{array}$ & & $x$ & $x$ & $x$ & & $x$ & $x$ & $x$ & & II \\
\hline 18 & $\begin{array}{l}\text { Multibody Simulation (MBS) } \\
{[34]}\end{array}$ & $x$ & $x$ & & & & & $x$ & & $x$ & VII \\
\hline 19 & $\begin{array}{l}\text { Node Link Diagram (NLD) } \\
{[32]}\end{array}$ & & $x$ & & & & & & $x$ & & $\mathrm{VI}$ \\
\hline 20 & $\begin{array}{l}\mathrm{NVH}^{5} \text { Model } \\
{[34]}\end{array}$ & $x$ & $x$ & & & & & $x$ & & $x$ & VII \\
\hline 21 & $\begin{array}{l}\begin{array}{l}\text { Parametric Associativity Graph } \\
\text { (PAG) } \\
{[26]}\end{array} \\
\end{array}$ & & $x$ & & & & & & $x$ & $x$ & IV \\
\hline 22 & $\begin{array}{l}\text { Product Architecture } \\
{[48]}\end{array}$ & & & $x$ & & & $x$ & & $x$ & & VIII \\
\hline 23 & $\begin{array}{l}\text { Multi-view Product Model (MVP } \\
\text { Model) } \\
{[49]}\end{array}$ & & $x$ & & & & & & $x$ & & VIII \\
\hline 24 & $\begin{array}{l}\text { Product Structure Model } \\
{[50]}\end{array}$ & & $x$ & $x$ & & & $x$ & & & $x$ & IV \\
\hline 25 & $\begin{array}{l}\text { Prototype } \\
{[2]}\end{array}$ & & & & & $x$ & & $x$ & $x$ & $x$ & III \\
\hline 26 & $\begin{array}{l}\text { Pseudo Rigid Body Model (PRBM) } \\
{[51] \text { [52] [53] }}\end{array}$ & $x$ & $x$ & & & & & $x$ & & $x$ & VII \\
\hline 27 & $\begin{array}{l}\text { Remanufacturability Model (RM) } \\
{[54]}\end{array}$ & $x$ & $x$ & & & & & & & $x$ & VII \\
\hline 28 & $\begin{array}{l}\text { Model of Rihtaršič (Rihtaršič) } \\
{[55]}\end{array}$ & & $x$ & & & & & $x$ & $x$ & & 1 \\
\hline 29 & $\begin{array}{l}\text { SAPPhIRE }{ }^{6} \\
{[56]}\end{array}$ & & & $x$ & & & $x$ & $x$ & $x$ & & VI \\
\hline 30 & $\begin{array}{l}\text { Sketches } \\
{[2]}\end{array}$ & & $x$ & & & & $x$ & $x$ & $x$ & & 1 \\
\hline 31 & $\begin{array}{l}\text { Statistical Model } \\
{[57]}\end{array}$ & $x$ & $x$ & & & & & $x$ & & $x$ & VII \\
\hline 32 & $\begin{array}{l}\text { Symbolic Representations } \\
{[2]}\end{array}$ & & $x$ & & & & $x$ & $x$ & $x$ & & I \\
\hline 33 & $\begin{array}{l}\text { SysML }{ }^{7} \text { Model } \\
{[58][37][59] \text { [49] [60] [61] [62] }}\end{array}$ & & $x$ & $x$ & & & $x$ & $x$ & $x$ & & II \\
\hline 34 & $\begin{array}{l}\text { Working Space Model } \\
{[63]}\end{array}$ & & $x$ & & & & $x$ & $x$ & $x$ & & III \\
\hline
\end{tabular}

CAD computer-aided design, $C \& C^{2}$ model contact and channel, CPM characteristics properties modeling, FEM finite element method, $N V H$ noise vibration harshness, SAPPhIRE "State Action Parts Phenomenon Input ORgan Effect", SysML systems modeling language
Each product model is evaluated based on its description in the source and assigned to the categories of depiction and information. The models are listed alphabetically. When a model does not have a name of its own, it is listed as "model of [author]". For the models listed in the table, additional research was conducted to identify each model's original source.

In total, 34 product models were found. The models function trees (\#12), models according to He (\#16), and models based on Gero (\#17) contain different variants of a product model that follow the same basic modeling principle. They are combined in one entry due to their similarity. In some of the identified publications, more than one product model is described. These publications are assigned to the product model on which they focus. For example, Leu et al. [20] use function trees (\#12) and other models to derive their axiomatic design model (\#2). This publication is assigned to the axiomatic design model, as this is its focus. Nagel et al. [38] integrate function trees (\#12) in system boundaries and different states of the product to study the flow of energy, material, and information throughout different states of the system. This is assigned to function trees (\#12), as it is the main focus of the model.

A total of 28 of the 34 product models include a graphical depiction. The presented instances of product models are used as a dataset for the structuring approach with the product model framework to investigate research question 2.

\subsection{Integration of findings into the product model framework}

The product model framework is built up according to four of the five categories of Andreasen et al. [2]. The category of communication is excluded from the framework, as differentiation of product models according to their ability to support communication would go beyond the scope of this contribution. It would require a differentiated view of the communication purpose and the participants of the communication.

In the built framework, the eight clusters are represented by Roman numerals (I to VIII). The cluster V (capture the unknown/design) is eliminated, because the definition of capture the unknown and the understanding of product models for design exclude combination in one product model. This leaves a total of seven clusters for the product models that are shown in Fig. 2. The visualization of these clusters is similar to the framework developed by Wynn and Clarkson [7], which has proven value in presenting large amounts of information in a structured way. The assignment of a product model to the cluster is based on its description and usage in the reference literature. It only considers the product model as it is described in 
Fig. 2 The product model framework

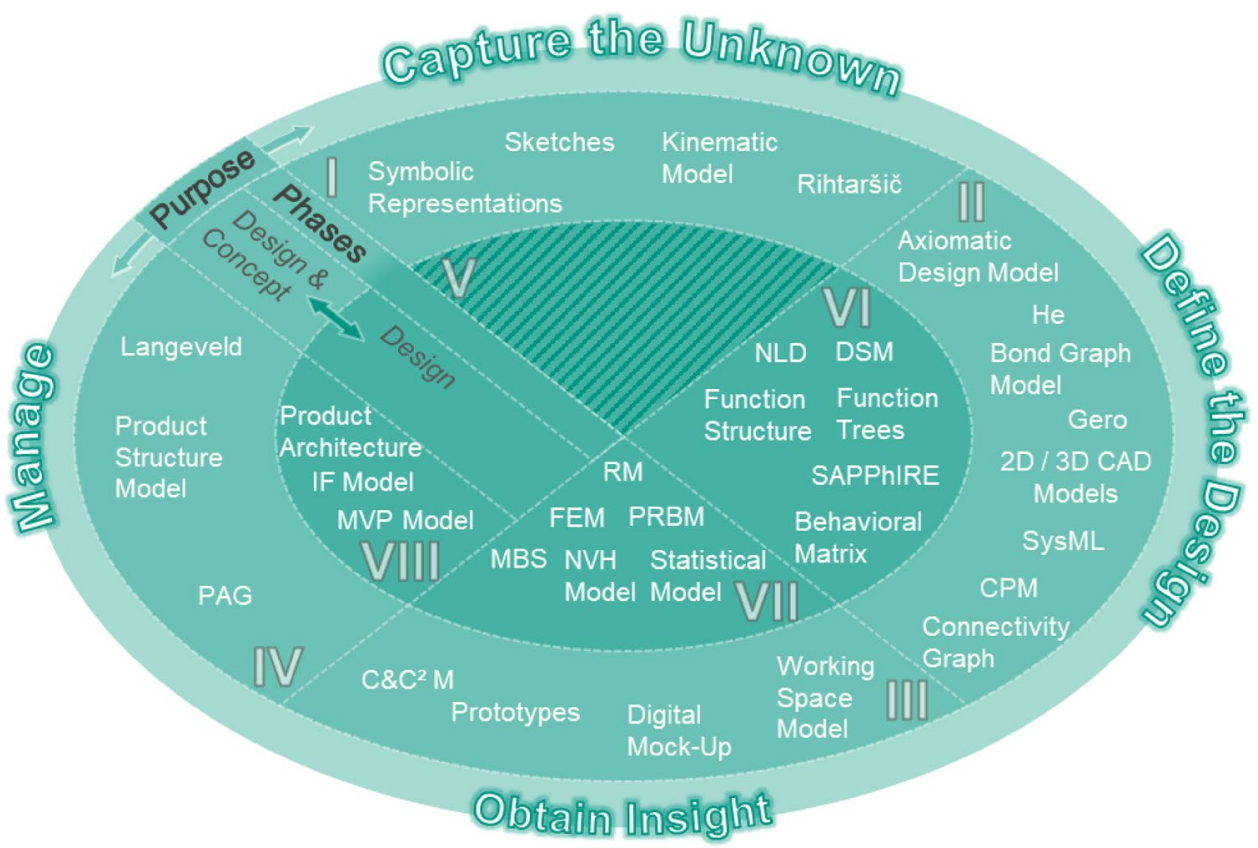

the instance that has been found in research. The original sources of the product models are not considered. For the product models that have not been described, but simply used in literature (like FEM models), it is referred to standard textbooks like Vajna et al. [64] for a state-of-theart description of the model. Abbreviations in Fig. 2 are explained in Table 2, where the product models are listed with the source and detailed aspects.

\section{The guideline for model selection}

As described in the Materials and Methods section, the guideline is proposed for a structured product model selection process in embodiment design. This guideline is inspired by the SPALTEN problem solving methodology described in [65]. It embeds the described framework and table into the problem solving process. Figure 3 depicts the steps of the guideline.

To further illustrate the intended way to work with the guideline, the steps are explained based on two examples from a study on an impact wrench. For details on the study, see [66].

Situation analysis In the first step of the guideline, the situation must be analyzed. The task and its boundary conditions are explained, from which the phase of the embodiment design as well as the purpose of product models to be used in the task can be derived. In the example of the impact wrench, understanding of the system's dynamic behavior is necessary to improve the precision of its torque application. The simple Coulomb's friction model used in most calculations of bolt tightening with

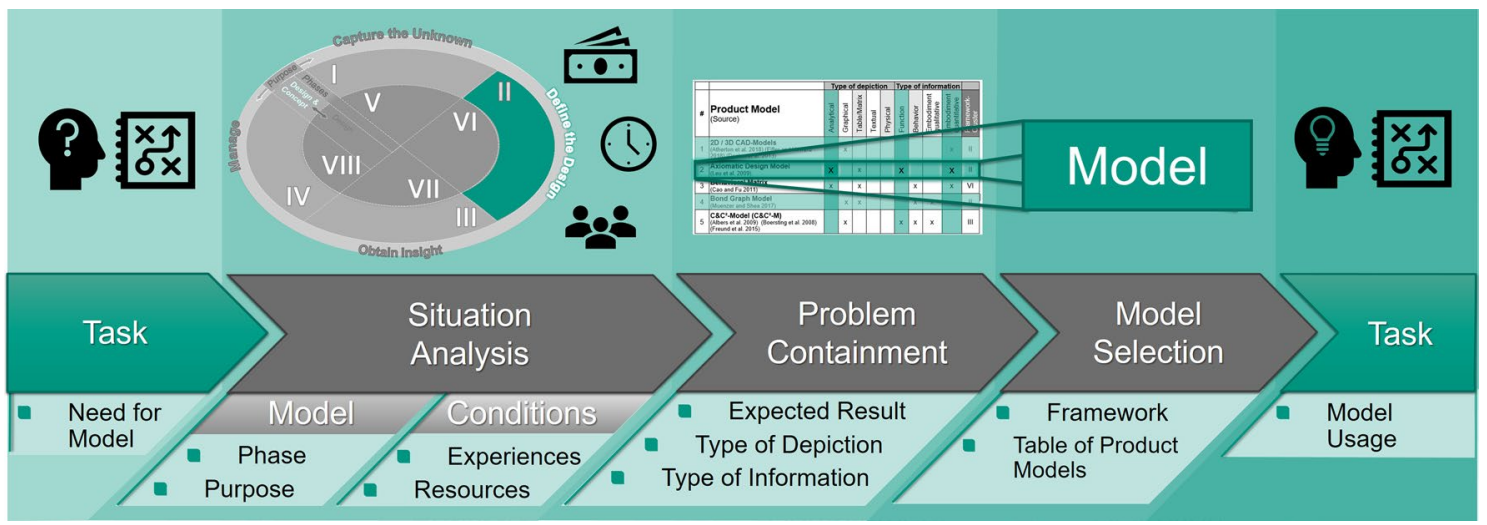

Fig. 3 Flowchart of the guideline 
an impact wrench comes with a high tightening factor of 2.5-4.0. This factor is necessary to ensure a robust bolt connection with this high uncertainty in the calculation model. To reduce this uncertainty, a product model of the impact wrench should be built, which allows for a more precise simulation of the kinematics and forces in the impact wrench. The design of the impact wrench already exists and is available as a 3D-CAD model and a physical reference product. The phase in this situation is the "design phase," as the product is already defined. The purpose for using a product model is "obtain insight". The resource is a test rig to investigate the dynamic behavior of the impact wrench. This defines the cluster of the framework, from which the product model is chosen later on.

Problem containment In the next step, the problem has to be contained to identify a suitable product model of the cluster. Here, the necessary aspects of the product model to solve the problem or to fulfill the given task need to be stated clearly. For this, it is useful to explain an expected result of the modeling process. In the case of the impact wrench, the task is not only to understand the mechanics, but to simulate its behavior quantitatively as well. This requires a product model with an analytical depiction of the system and behavior and quantitative embodiment as type of information.

Model selection When the situation and the problem are sufficiently clear, the product model can be selected. After selection of the cluster, Table 2 provides the overview of the different aspects of the included product models. If this leaves more than one product model, a decision should be made based on the resources and experience gained from the product models. When the framework does not contain any product model that could be used for the task, it is possible to either conduct a search for a product model that has not been included in the framework or to modify a product model that is close to fulfilling the task. To investigate the impact wrench, the product model is selected from cluster VII. From Table 2, information can be retrieved about which product models of cluster VII fulfill the requirements for an analytical depiction, quantitative embodiment information, and information about the behavior. This leaves multi-body simulation models (MBS), finite element method models (FEM), and the pseudo-rigid body model (PRBM). Since the processes in an impact wrench are dynamic, an MBS model is developed.

The MBS model is then used to investigate the dynamic behavior of the impact wrench. When validating the product model, an unknown behavior occurs. Apart from the impact of the hammer on the anvil, the physical measurement signal sometimes shows another low peak of the measured torque that does not show up in the simulation data and cannot be explained by the MBS model. An example of this phenomenon is given in Fig. 4.

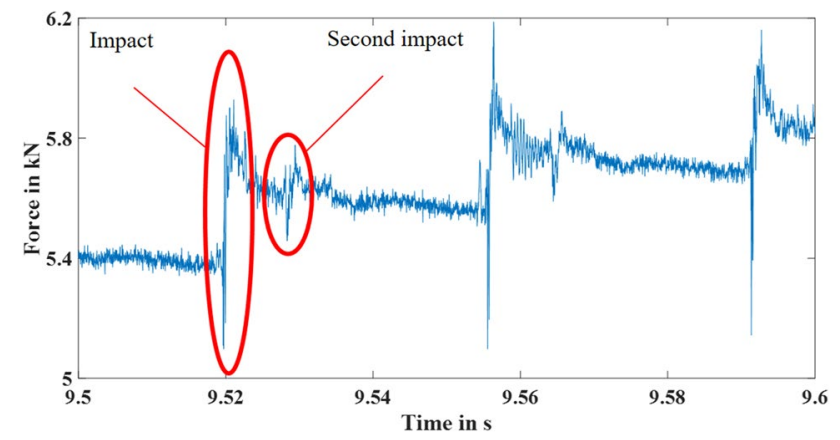

Fig. 4 Phenomenon in the preload force of a screw connection fastened by an impact wrench [66]

Under certain conditions, the impact is followed by a second impact. The reasons for this second impact are unknown. With the existing product models, this phenomenon cannot be explained. This leads to a new situation, where another product model is required to understand this phenomenon and reduce uncertainty in the MBS model. As the design engineers did not expect this behavior, their mental models did not cover it. Analysis of the 3D-CAD model and the MBS model does not provide any solutions, as they are built on the mental models. Here, an additional product model is required to understand this phenomenon. Using the guideline again yields a lot of information that is available on the requirements and restraints. However, the problem has changed and, consequently, the product model requirements change from "quantitative embodiment" information and an "analytical" description to a "physical" depiction in an experimental setup and a graphical depiction of relations of embodiment and behavior to support the process of gaining insight. This leads to the selection of a prototype and a $C \& C^{2}$ model from the cluster III "concept and design" and "obtain insight". The prototype enables the researchers to observe the processes in situ and two new states of the hammer mechanism are found, where the hammer does not move over the anvil, but instead brushes the top or hits the edge, thus creating the second impact in the measurement signal. The $C \& C^{2}$ model is used to obtain insights into relevant design parameters for the observed behavior. Based on these insights, the MBS model is improved [66].

\section{Discussion}

The findings of the systematic literature review confirm the premise of the paper that a large variety of product models exists in embodiment design. Research question 1 "Which product models are currently used or developed in embodiment design research?" can only be answered 
in a limited range, as probably not all models described in literature are identified. This might be due to different use of keywords in the model description or publication at conferences without accessible proceedings. Many product models found in this research were also mentioned in the collection of product models associated with mechatronics presented by Weidmann et al. [12]. This has been expected, as the mechanics discipline of Weidmann's research also comprises embodiment design. However, more focused research of this contribution on embodiment design yielded a variety of specialized models, such as CPM, DSM or C\& $C^{2} M$.

Although product models might be lacking, it can be assumed that the result of the literature research produces a large variety of product models that are currently used or under research, as it covers popular platforms of the community on an abstract level of detail. Still, it should be mentioned that product models without scientific publications are not accessible by this approach.

Research question 2 "Are the proposed categories suited for an application-oriented categorization of product models for embodiment design?" is answered by the developed framework and categorization. The seven clusters of the framework provide an overview of product models for a suggested purpose and phase to use the product models. Since the viewing level of the framework does not provide sufficient detail to select a product model, the framework has to be combined with the categorization based on the type of information and type of depiction. However, allocation of the phase category of the framework turned out to be difficult, as most of the identified models did not contain any description of when they might be used in embodiment design. Therefore, the only differentiation made was whether the necessary input is available in the design phase (parameters, CAD models, etc.) or not. Classification of the product model framework also revealed an ambiguity in identifying the main application of the model. Stronger criteria for sorting the methods according to their main application were required. The questions designed to categorize models for the framework helped eliminate part of this ambiguity and led to a more objective categorization. The answer of research question 2 is that the product models can be categorized using the categories proposed, but the categorization process is also influenced by the understanding of the category definition and the description of the product model.

The guideline is a result of the findings from research questions 1 and 2 as well as of experience gained from a modeling project. It is an approach to structured product model selection based on the framework and the categorization of the product models from the practitioner's point of view. Definition of the modeling purpose and phase of embodiment design should guide users towards the suitable cluster of models. With the further specified needs for type of depiction and information included in the product model, a product model can be selected. This systematic approach may support the selection of product models in embodiment design. However, the usefulness of this approach to product model selection still needs to be validated in practice.

\section{Conclusion and outlook}

Product modeling is widely spread and diverse in engineering practice and research. This leaves design engineers with an expanding variety of product models and tools to choose from in the embodiment design process. The proposed framework can help to identify product models in embodiment design, as it provides a structure with modeling application criteria and a reference for the engineering phase in which certain product models can support design engineers. However, further research is needed, since the product models included at this point are based on a search in scientific publications. This excludes commercial tools and specialized product models developed for industry as well as product models presented without mentioning the chosen search terms. The product model framework presented here represents the basis for continuing research. This framework gives practitioners in embodiment design the chance to reduce the variety of product models available to one set of product models tailored to their needs, resources, and competences available in their design project.

Future research will continue to further detail the product model framework in terms of model details that should be included and how the product models should be categorized. With the developed framework, the question of which product models are suited can be answered on a high level, assuming that the understanding of the categories matches the definitions presented in this paper. With a more detailed framework, it can be determined how far the range of different product models goes. This will support research on limitations of product models and might serve as a basis for identifying and building of intersections of different product models.

\section{Compliance with ethical standards}

Conflict of interest All authors declare that they have no conflict of interest. 


\section{References}

1. Stachowiak H (1973) Allgemeine Modelltheorie. Springer, New York

2. Andreasen MM, Hansen CT, Cash P (2015) Conceptual design. Springer, Cham

3. "VDI-Richtlinie 2221:2018-03 Blatt1," 2018

4. Lindemann U (2009) Methodische Entwicklung technischer Produkte. Springer, Berlin

5. Vajna S, Clement S, Jordan A, Bercsey T (2005) The autogenetic design theory: an evolutionary view of the design process. $J$ Eng Des 16(4):423-440

6. Albers A, Reiss N, Bursac N, Richter T (2016) iPeM-integrated product engineering model in context of product generation engineering. Procedia CIRP 50:100-105

7. Wynn DC, Clarkson PJ (2018) Process models in design and development. Res Eng Des 29(2):161-202

8. Ehrlenspiel K, Meerkamm H (2017) Integrierte Produktentwicklung: Denkabläufe, Methodeneinsatz, Zusammenarbeit, 6th edn. Carl Hanser Verlag GmbH \& Co. KG, München

9. Meboldt M, Matthiesen S, Lohmeyer Q (2012) The dilemma of managing iterations in time-to-market development processes. In: 2nd international workshop on modelling and management of engineering processes, Cambridge, UK, pp 127-139

10. Matthiesen S (2011) Seven years of product development in industry-experiences and requirements for supporting engineering design with 'thinking tools'. In: Proceedings of the 18th international conference on engineering design, Copenhagen, Denmark, pp 236-245

11. Fuchs DK (2005) Konstruktionsprinzipien für die Problemanalyse in der Produktentwicklung. Ph.D. thesis, Lehrstuhl für Produktentwicklung, München

12. Weidmann $D$, Isemann $M$, Kandlbinder $P$, Hollauer $C$, Kattner $N$, Becerril L, Lindemann U (2017) Product models in mechatronic design: literature analysis on the interdisciplinary character of product models. In: 2017 Portland international conference on management of engineering and technology (PICMET), Portland, OR, pp 1-7

13. Dresch A, Lacerda DP, Antunes JAV (2015) Design Science Research. In: Dresch A, Lacerda DP, Antunes JAV Jr (eds) Design science research. Springer, Cham, pp 67-102

14. Pahl G, Beitz W, Feldhusen J, Grote K-H (2007) Engineering design. Springer, London

15. Matthiesen $S$ (2019 in print) Prozess und Methoden der Gestaltung. In: Bender B, Gericke K (eds) Pahl/Beitz Konstruktionslehre, 9 th edn. Springer, Berlin

16. Gero JS, Kannengiesser U (2014) The function-behaviourstructure ontology of design. In: Chakrabarti A, Blessing LTM (eds) An anthology of theories and models of design: philosophy, approaches and empirical explorations. Springer, Berlin, pp 263-283

17. Atherton $M$, Jiang $P$, Harrison D, Malizia A (2018) Design for invention: annotation of functional geometry interaction for representing novel working principles. Res Eng Des 29(2):245-262

18. Eifler T, Howard TJ (2018) The importance of robust design methodology: case study of the infamous GM ignition switch recall. Res Eng Des 29(1):39-53

19. Dantan JY, Qureshi AJ, Antoine JF, Eisenbart B, Blessing L (2013) Management of product characteristics uncertainty based on formal logic and characteristics properties model. CIRP Ann 62(1):147-150

20. Leu MC, Wu JC, Liu XF (2009) Axiomatic functional and objectoriented product design framework. CIRP Ann 58(1):147-152
21. Cao DX, Fu MW (2011) A knowledge-based prototype system to support product conceptual design. Comput Aided Des Appl 8(1):129-147

22. Muenzer C, Shea K (2017) Simulation-based computational design synthesis using automated generation of simulation models from concept model graphs. J Mech Des, vol 139, no 7, 71101, Paper No: MD-16-1491

23. Albers A, Braun A, Clarkson J, Enkler H-G, Wynn D (2009) Contact and channel modelling to support early design of technical systems. In: International conference on engineering design ICED 09, Stanford, CA, USA, pp 161-174

24. Boersting P, Keller R, Alink T, Eckert CM, Albers A, Clarkson PJ (2008) The relationship between functions and requirements for an improved detection of component linkages. In: 10th international design conference, DESIGN 2008, Dubrovnik, Croatia, pp 309-316

25. Freund T, Kloberdanz H, Wuertenberger J, Lotz J (2015) An Approach to Analysing Interface Uncertainty using the Contact and Channel Model. In: Weber C et al (eds) DS/design society, vol. 80, 6, Design for life: the 20th international conference on engineering design (ICED 15); 27th-30th July 2015, Politecnico di Milano, Italy.Design Society, Glasgow, pp 53-62

26. Ameri F, Summers JD, Mocko GM, Porter M (2008) Engineering design complexity: an investigation of methods and measures. Res Eng Des 19(2-3):161-179

27. Köhler C (2009) Technische Produktänderungen - Analyse und Beurteilung von Lösungsmöglichkeiten auf Basis einer Erweiterung des CPM/PDD-Ansatzes. Dissertation, Schriftenreihe Produktionstechnik, Universität des Saarlandes, Saarbrücken

28. Zhan W, Huang P (2018) Physics-based modeling for lap-type joints based on the Iwan model. J Tribol, vol 140, no 5, 51401, Paper No: TRIB-17-1278

29. Weber C (2014) Modelling products and product development based on characteristics and properties. In: Chakrabarti A, Blessing LTM (eds) An anthology of theories and models of design: philosophy, approaches and empirical explorations. Springer, Berlin, pp 327-352

30. Weber C (2005) CPM/PDD - an extended theoretical approach to modelling products and product development processes. In: Proceedings of the 2 nd German-Israeli symposium. FraunhoferIRB-Verlag, Stuttgart, Germany, pp 159-179

31. Eppinger SD, Browning TR (2012) Design structure matrix methods and applications. MIT Press, Cambridge

32. Bonev M, Hvam L, Clarkson J, Maier A (2015) Formal computeraided product family architecture design for mass customization. Comput Ind 74:58-70

33. Browning TR (2016) Design structure matrix extensions and innovations: a survey and new opportunities. IEEE Trans Eng Manag 63(1):27-52

34. Danjou S, Lupa N, Koehler P (2008) Approach for automated product modeling using knowledge-based design features. Comput Aided Des Appl 5(5):622-629

35. Riascos R, Levy L, Stjepandić J, Fröhlich A (2015) Digital Mockup. In: Stjepandić J, Wognum N, Verhagen WJC (eds) Concurrent engineering in the 21st century. Springer, Cham, pp 355-388

36. Rajaguru P, Stoyanov S, Tang Y, Bailey C, Claverley J, Leach R, Topham D (2010) Numerical modelling methodology for design of miniaturised integrated products - an application to 3D CMM micro-probe development. In: 201011 th international thermal, mechanical and multi-physics simulation, and experiments in microelectronics and microsystems (EuroSimE), Bordeaux, France, pp 1-8

37. Chakrabarti A, Shea K, Stone R, Cagan J, Campbell M, Hernandez NV, Wood KL (2011) Computer-based design synthesis research: an overview. J Comput Inf Sci Eng, vol 11, no 2, 21003, Paper No: TRIB-17-1278 
38. Nagel RL, Stone RB, Hutcheson RS, McAdams DA, Donndelinger JA (2008) Function design framework (FDF): integrated process and function modeling for complex systems. In: Volume 4: 20th international conference on design theory and methodology; second international conference on micro- and nanosystems, Brooklyn, New York, USA, pp 273-286

39. Gericke K, Eisenbart B (2017) The integrated function modeling framework and its relation to function structures. AIEDAM 31(04):436-457

40. Gao FJL, Qian ZQ, Wang XJ, Bi ZM, Zhang WJ (eds) A novel approach to embodiment design of a robotic system for maximum workspace. In: 2015 IEEE 10th conference on industrial electronics and applications (ICIEA), pp 539-544

41. Langeveld $L$ (2011) Product design with embodiment design as a new perspective. In: Industrial design-new frontiers, Rijeka. InTech, Croatia, pp 121-146

42. He B, Song W, Wang Y (2013) A feature-based approach towards an integrated product model in intelligent design. Int J Adv Manuf Technol 69(1-4):15-30

43. He B, Song W, Wang Y (2015) Computational conceptual design using space matrix. J Comput Inf Sci Eng, vol 15, no 1, 11004, Paper No: JCISE-12-1134

44. He B, Huang $S$ (2016) Functional synthesis of mechanisms under cost consideration. Proc Inst of Mech Eng Part B J Eng Manuf 230(1):91-99

45. Mokhtarian H, Coatanéa $E$, Paris H (2017) Function modeling combined with physics-based reasoning for assessing design options and supporting innovative ideation. AIEDAM 31(04):476-500

46. Goel AK, Vattam S, Wiltgen B, Helms M (2012) Cognitive, collaborative, conceptual and creative: Four characteristics of the next generation of knowledge-based CAD systems-a study in biologically inspired design. Comput Aided Des 44(10):879-900

47. Gu C-C, Hu J, Peng Y-H, Li S (2012) FCBS model for functional knowledge representation in conceptual design. J Eng Des 23(8):577-596

48. Feldhusen J, Grote K-H (eds) (2013) Pahl/Beitz Konstruktionslehre: Methoden und Anwendung erfolgreicher Produktentwicklung, 8th edn. Springer, Berlin

49. Rasoulifar G, Prudhomme G, Brissaud D (2012) Coupling engineering knowledge with product design knowledge by the means of multiple view product model. In: Volume 3: advanced composite materials and processing; robotics; information management and PLM; Design Engineering, Nantes, France, pp 777-783

50. Baxter D, Gao J, Case K, Harding J, Young B, Cochrane S, Dani S (2008) A framework to integrate design knowledge reuse and requirements management in engineering design. Robot Comput Integr Manuf 24(4):585-593

51. Berselli G, Meng Q, Vertechy R, Castelli VP (2016) An improved design method for the dimensional synthesis of flexure-based compliant mechanisms: optimization procedure and experimental validation. Meccanica 51(5):1209-1225

52. Bilancia P, Berselli G, Bruzzone L, Fanghella $P$ (2017) A practical method for determining the pseudo-rigid-body parameters of spatial compliant mechanisms via CAE tools. Procedia Manuf 11:1709-1717

53. He B, Cao JT, He XL, Jin ZX, Fang ML (2012) Lifting platform in jack-up offshore platform based on virtual prototyping. AMM 198-199:154-157
54. Fang HC, Ong SK, Nee AYC (2014) Product remanufacturability assessment based on design information. Procedia CIRP 15:195-200

55. Rihtaršič J, Žavbi R, Duhovnik J (2012) Application of wirk elements for the synthesis of alternative conceptual solutions. Res Eng Des 23(3):219-234

56. Sarkar B, Chakrabarti A, Ananthasuresh GK (2017) Synthesis of feedback-based design concepts for sensors. Res Eng Des 28(1):131-151

57. Künne B, Wieczorek D (eds) Research to optimize the embodiment design of modules and components used in roller conveyors. In: 2010 IEEE international conference on automation and logistics, pp 495-500

58. Wölkl S, Shea K (2009) A computational product model for conceptual design using SysML. In Volume 2: 29th computers and information in engineering conference, parts $A$ and $B$, San Diego, California, USA, pp 635-645

59. Zingel C, Albers A, Matthiesen S, Maletz M (2012) Experiences and advancements from one year of explorative application of an integrated model-based development technique using $C \& C$ 2-A in SysML. In vol. 39, IAENG international journal of computer science. International Association of Engineers, Hong Kong, pp 165-181

60. Eisenbart B, Gericke K, Blessing LTM (2017) Taking a look at the utilisation of function models in interdisciplinary design: insights from ten engineering companies. Res Eng Des 28(3):299-331

61. Zheng C, Hehenberger P, Le Duigou J, Bricogne M, Eynard B (2017) Multidisciplinary design methodology for mechatronic systems based on interface model. Res Eng Des 28(3):333-356

62. Gadeyne K, Pinte G, Berx K (2014) Describing the design space of mechanical computational design synthesis problems. Adv Eng Inf 28(3):198-207

63. Beetz J-P, Schlemmer PD, Kloberdanz H, Kirchner E (2018) Using the new working space model for the development of hygienic products. In: 15th international design conference, Dubrovnik, Croatia, pp 985-996

64. Vajna S, Weber C, Zeman K, Hehenberger P, Gerhard D, Wartzack $S$ (2018) CAx für Ingenieure: Eine praxisbezogene Einführung, 3rd edn. Springer, Berlin

65. Albers A, Reiß N, Bursac N, Breitschuh J (2016) 15 years of SPALTEN problem solving methodology in product development. In: 12th biennial norddesign 2016 conference, NordDesign 2016; Norwegian University of Science and Technology (NTNU) Trondheim, Norway, pp 411-420

66. Matthiesen S, Wettstein A, Grauberger P (2018) Analysis of dynamic system behaviour using sequence modelling with the C\&C $C^{2}$-Approach-a case study on a power tool hammer mechanism. In: NordDesign 2018, Linköping, Sweden, Paper No.: 101, pp $1-10$

Publisher's Note Springer Nature remains neutral with regard to jurisdictional claims in published maps and institutional affiliations. 